\title{
Neural Regulation of the Circadian Vasopressin Rhythm in Cerebrospinal Fluid: A Pre-eminent Role for the Suprachiasmatic Nuclei ${ }^{1}$
}

\author{
WILLIAM J. SCHWARTZ ${ }^{2 \star}$ AND STEVEN M. REPPERT‡
}

*Neuroendocrine Research Laboratory and Laboratory of Neurology, and $\ddagger$ Laboratory of Developmental Chronobiology and Children's Services, Massachusetts General Hospital and Harvard Medical School, Boston, Massachusetts 02114

\begin{abstract}
The neuroanatomical system responsible for the generation and expression of the circadian vasopressin rhythm in cerebrospinal fluid (CSF) is investigated. CSF was serially withdrawn in individual, unanesthetized, unrestrained rats after neuroendocrine extirpations or stereotaxic brain lesions were made; the peptide was assayed using a sensitive and specific radioimmunoassay.

Hypophysectomy or pinealectomy did not eliminate vasopressin from CSF; both day and night-time peptide levels in hypophysectomized rats were elevated above control levels. Complete lesions of the suprachiasmatic nuclei (SCN) abolished both the rhythm and in most cases the measurable level of peptide in CSF. Neither lesions of the paraventricular nuclei nor hypothalamic knife cuts interrupting most neural efferents from the SCN had this effect; in these cases, vasopressin rhythms persisted with diminished amplitude.

Our results suggest that the circadian CSF vasopressin rhythm is produced by a neural system topographically separate from the classical magnocellular hypothalamo-neurohypophyseal system for the secretion of peptide into blood. The SCN are an important component of this new system and are necessary for the generation of the CSF rhythm.
\end{abstract}

The neurohypophyseal hormone, arginine vasopressin, has been measured in the cerebrospinal fluid (CSF) of several mammalian species (Robinson, 1983). The principal source of the peptide in CSF is not blood, since permeability (if any) of the blood-brain barrier to vasopressin is too low to account for the levels in CSF (Wang et al., 1981; Ang and Jenkins, 1982; Stark et al., 1984).

Recently, the concept has emerged that release of brain vasopressin into the CSF is both anatomically and functionally separate from secretion of neurohypophyseal vasopressin into the bloodstream. This idea was initially based on the observations that vaso-

Received January 15, 1985; Revised March 29, 1985;

Accepted April 22, 1985

We thank Matthew Morton, Harley Heath, Robert Coleman, Jason Swedlow, and Mark Banister for technical assistance; Olgerts Zvaigne for help with histologic preparations; and Dr. H. Elliott Albers for expert assistance with the time-series analysis. This work was supported by National Institute of Neurological and Communicative Disorders and Stroke Teacher-Investigator Award KO7 NS 00672 (W. J. S.), March of Dimes Basil O'Connor Starter Research Grant 5-433 (W. J. S.), and United States Public Health Service Grant NS 18755 (S. M. R.).

${ }^{2}$ To whom correspondence should be addressed. pressin is present in CSF after hypophysectomy (Dogterom et al., 1977) and in humans with diabetes insipidus (Luerssen and Robertson, 1980). Anatomical studies have since shown that the peptide is found in neurons outside the classical magnocellular hypothalamoneurohypophyseal system (Buijs, 1983; Kozlowski et al., 1983 Sofroniew, 1983); the cell bodies of these neurons appear to be distinctly different from the cell bodies that project to pituitary gland (Swanson and Sawchenko, 1983). Furthermore, vasopressin release into the CSF can be dissociated from its release into the systemic circulation by various physiological and pharmacological stimuli (Mens et al., 1980; Wang et al., 1982; Morris et al., 1984; Coleman and Reppert, 1985), although conflicting results have been reported (Doris and Bell, 1984; Szczepanska-Sadowska et al., 1984). These data support the notion that the peptide has specific brain functions in addition to its well established role in the regulation of water balance.

We and others have observed prominent daily rhythms of CSF vasopressin concentrations in cats (Reppert et al., 1981), monkeys (Perlow et al., 1982), rats (Mens et al., 1982; Schwartz et al., 1983), guinea pigs (Robinson and Jones, 1982), and rabbits (Gunther et al., 1984). This hormonal rhythm is endogenously generated (circadian), i.e., it is sustained even in the absence of periodic lighting or other external timing cues and synchronized to the environmental light-dark cycle (Reppert et al., 1982; Schwartz et al., 1983).

In this paper, we examine the neuroanatomical system responsible for the generation and expression of the CSF vasopressin rhythm and show that it is different from the classical hypothalamo-neurohypophyseal secretory system. For these studies, we measured the peptide rhythm in individual rats after neuroendocrine extirpations or stereotaxic brain lesions were made.

\section{Materials and Methods}

\section{Animals}

Adult male Long-Evans rats (Charles River Breeding Laboratories, Wilmington, MA) were housed individually in diurnal lighting (12 hr of light per day with lights on from 7:00 A.M. to 7:00 P.M.). Light was provided by 15-W cool white fluorescent tubes delivering an intensity of $700 \mathrm{lux}$ at the midcage level. Purina Rat Chow and water were freely available, and the time of day of routine care was randomized.

\section{Surgical Procedures}

Hypophysectomy. Hypophysectomy was performed by the supplier on rats weighing 360 to $380 \mathrm{gm}$. Animals were anesthetized with ether, and the entire pituitary gland was removed after a parapharyngeal exposure. Rats were then housed by the supplier for 2 weeks to stabilize their weights at 280 to $300 \mathrm{gm}$; we maintained them with supplemental orange slices and water containing $5 \mathrm{gm} / 100 \mathrm{ml}$ of sucrose, $0.2 \mathrm{gm} / 100 \mathrm{ml}$ of NaCl, $8.3 \mathrm{mg} /$ 
$100 \mathrm{ml}$ of $\mathrm{KCl}, 3.5 \mathrm{mg} / 100 \mathrm{ml}$ of $\mathrm{CaCl}_{2}$, and $1.7 \mathrm{mg} / 100 \mathrm{ml}$ of $\mathrm{MgCl}_{2}$. Sham hypophysectomy (gland exposure without removal) was also performed by the supplier.

Pinealectomy. We performed pinealectomy on rats weighing 225 to 250 $\mathrm{gm}$. Animals were anesthetized with ether and placed in a Kopf stereotaxic apparatus. The cranium was exposed through a midline skin incision, and a trephine was used to remove a section of bone at the junction of the sagittal and lambdoidal sutures. The superficial pineal giand was grasped with forceps and pulled out through the confluence of the sinuses. The skull defect was plugged with a piece of gelatin foam.

Stereotaxic brain lesions. We made stereotaxic brain lesions on rats weighing 280 to $320 \mathrm{gm}$. Animals were anesthetized with pentobarbital (50 $\mathrm{mg} / \mathrm{kg}$, i.p.), treated with atropine sulfate $(0.1 \mathrm{mg}, i . \mathrm{m}$.) and penicillin $\mathrm{G}$ $(150,000$ units, i.m.), and placed in the stereotaxic apparatus.

Bilateral lesions of the suprachiasmatic nuclei (SCN) were made by passing $4 \mathrm{~mA}$ of current for $10 \mathrm{sec}$ through bipolar platinum-iridium electrodes insulated to within $0.5 \mathrm{~mm}$ of their tips (A, $+7.5 \mathrm{~mm}$ anterior to ear bars; $\mathrm{L}$, $\pm 0.3 \mathrm{~mm}$ from midline, $V,-9.5 \mathrm{~mm}$ from skull; incisor bar at the interaural line). For sham lesions, electrodes were placed but no current passed.

Bilateral lesions of the hypothalamic paraventricular nuclei were made by rotating a triangular microknife. The knife was shaped similar to the coronal cross-section of the nuclei by bending 26 gauge stainless steel tubing into a loop and filling it with solder. The cutting edge was $1.0 \mathrm{~mm}$ in height and approximately $4.0 \mathrm{~mm}$ in diameter when the tip was rotated. The knife was rigidly held within a 21 gauge guide tube, and this assembly was lowered into the brain with the knife tip pointing anteriorly in the midline $\left(A_{1}+6.4 \mathrm{~mm}\right.$ anterior to ear bars; $L, 0.0 \mathrm{~mm}$ in the midline; $V,-8.5 \mathrm{~mm}$ from skull; incisor bar $7.5 \mathrm{~mm}$ below the interaural line). For sham lesions, the knife was lowered but not rotated.

To interrupt neural efferents from the SCN, hypothalamic knife cuts were made by rotating a wire microknife. This knife was constructed by bending a length of 26 gauge solid stainloss stccl tubing to form a cutting edge 1.5 $\mathrm{mm}$ in height and approximately $3.0 \mathrm{~mm}$ in diameter when the tip was rotated. The knife was carried within a 21-gauge guide tube and lowered into the brain at a $15^{\circ}$ caudal inclination $(A,+7.7 \mathrm{~mm}$ anterior to ear bars; $L$, $0.0 \mathrm{~mm}$ in the midline; $\mathrm{V},-9.0 \mathrm{~mm}$ from skull; incisor bar at the interaural line).

\section{CSF collection}

All rats were cannulated when they weighed 280 to $320 \mathrm{gm}$, i.e., 1 month after hypophysectomy, 2 weeks after pinealectomy, or at the same time that stereotaxic brain lesions were made. CSF cannulae were constructed, irmplanted into the cisterna magna, and anchored to the skull as previously described (Schwartz et al., 1983).

Each rat was individually housed in a wire-mesh sampling cage within its own light-controlled isolation chamber (600 lux at the middle of each cage). Animals regained their preoperative body weights after 5 to 7 days. At this time, rats with stereotaxic brain lesions were blinded by bilateral orbital enucleation under ether anesthesia. ${ }^{3}$ Approximately 2 weeks after cisternal cannulation, animals were tethered by a system that allowed them to be undisturbed and freely moving while $150 \mu \mathrm{l}$ of CSF were repeatedly withdrawn every $4 \mathrm{hr}$ for several days. Removed CSF was stored at $-40^{\circ} \mathrm{C}$ until analysis

\section{Radioimmunoassay}

CSF vasopressin concentrations. Concentrations of CSF vasopressin were measured using Skowsky antiserum, R-71 (Skowsky et al., 1974). The assay procedure for analysis of vasopressin in unextracted CSF has been rigorously validated (Reppert et al., 1982). Data were analyzed using a computer program based on a log-logit linearization of the standard curve (Rodbard, 1974). The limit of assay sensitivity was 0.08 micro-units/tube $(0.48$ micro units $/ \mathrm{ml}$ of CSF). The intra-assay coefficient of variation was $10 \%$ and the interassay coefficient of variation was $13 \%$.

Pineal melatonin concentrations. Concentrations of pineal melatonin were measured using a modification (Tamarkin et al., 1979) of the Rollag and Niswender (1976) procedure. Pineal glands were rapidly removed $(<2 \mathrm{~min}$ after sacrifice) and frozen at $-70^{\circ} \mathrm{C}$ on dry ice. Glands were later homoge-

\footnotetext{
${ }^{3}$ Animals were blinded so that the CSF vasopressin rhythm could be monitored in constant environmental conditions. Blinded adult mammals do not entrain to environmental light-dark cycles, and there is no evidence for extraocular photoreception in such animals (Nelson and Zucker, 1981; Underwood and Groos, 1982).
}

nized by sonication for $5 \mathrm{sec}$ in $120 \mu \mathrm{l}$ of $0.1 \mathrm{M}$ sodium phosphate buffer ( $\mathrm{pH} 6.8$ ) and assayed. The limit of assay sensitivity was $2 \mathrm{pg} /$ tube. The intraassay coefficient of variation was $10 \%$ and the interassay coefficient of variation was $20 \%$

\section{Drinking behavior}

Leads from the wire-mesh sampling cages and from the metal spouts of drinking tubes were wired to drinkometer relays (Lafayette Instruments, Lafayette, IN). A lick on the drinking tubc registered a pen deflection on an event recorder (Esterline Angus, Indianapolis, IN) so that the daily profiles of drinking behavior were monitored for each rat. For analytical purposes, the raw data were scored as number of drinkiriy bouts per 30-min interval (values ranged from 0 to 3 ).

Rhythmicity of the drinking activity of some rats was analyzed by computer using a program for linear-nonlinear least squares multiple periodic regression (Rummel et al., 1974). This program yields a $t$ and an $r^{2}$ value for all possible periods between 4.25 and $40.00 \mathrm{hr}$. Statistical significance was set at $p<$ 0.01

\section{Histology}

Location and extent of lesions were verified by light microscopic examination of cresyl violet-stained, $20-\mu \mathrm{m}$-thick frozen coronal sections. Sections were cut at $60-\mu \mathrm{m}$ intervals.

\section{Results}

Neuroendocrine extirpations. We first examined the possibility that vasopressin might gain access to CSF indirectly by secretion from neuroendocrine organs bordering the subarachnoid cisterns.

After sham hypophysectomy (Fig. 1), the CSF vasopressin rhythm was indistinguishable from that previously reported in intact animals (Schwartz et al., 1983). Vasopressin levels were low (at the limit of assay sensitivity) during the night and began to increase $2 \mathrm{hr}$ before lights-on. Levels reached peak values during midmorning, declined during the afternoon, and were at low levels $2 \mathrm{hr}$ before lights-off Actual hypophysectomy did not eliminate vasopressin from CSF; in fact, levels were elevated during both day and night (Fig. 1). Daily rhythms of vasopressin concentrations were still evident in individual animals (Fig. 1, especially rats $\mathrm{H}-12$ and $\mathrm{H}-16$ ), and peptide levels from 5:00 A.M. to 4:59 P.M. hr were higher (4.78 \pm 0.25 micro-units/ $\mathrm{ml}, \mathrm{SEM}$ ) than those frorr 5:00 P.M. to 4:59 A.M. hr (3.72 \pm 0.22 micro-units $/ \mathrm{ml}$ ) in the population of animals as a whole, but the individual profiles were quite variable.

Although the pineal gland apparently contains vasopressin (Buijs and Pevet, 1980; Fisher and Fernstrom, 1981), pinealectomy had no effect on the daily CSF vasopressin rhythm (Fig. 2).

Lesions of the SCN. Since the rhythm of CSF vasopressin concentrations is a true circadian rhythm, we next studied the effects of lesions of the SCN, the locus of a rat circadian clock (Moore, 1983).

Rats with complete SCN lesions also sustained damage to the preoptic area and to the anterior, periventricular, and anterior ventromedial hypothalamic nuclei (Fig. $3 A$ ). The paraventricular and supraoptic nuclei of the hypothalamus were spared in all cases, and the organum vasculosum of the lamina terminalis was not reproducibly involved. Visual inspection of drinking activity records from these lesioned animals showed no apparent circadian rhythms, as has been extensively reviewed in the literature (Moore, 1983).

The CSF vasopressin rhythm was abolished in all lesioned rats (Fig. 4), and in all animals but one (Fig. 4, rat S-23) the level of peptide was at or near the limit of assay sensitivity. Drinking and CSF vasopressin rhythms were clearly evident after sham lesions (Fig. 5). The peptide rhythm was sometimes sustained (Fig. 5, rats S-24 and S-31) when lesions only partially destroyed the SCN. Although the number of animals was small, no relationship was apparent between rhythm persistence and volume or location of remaining SCN, extent or sites of nonspecific damage, or degree of residual rhythmicity of drinking activity.

Thus, the SCN are clearly necessary for expression of the circadian CSF vasopressin rhythm. Since vasopressin is contained within 
SHAM HYPOPHYSECTOMY
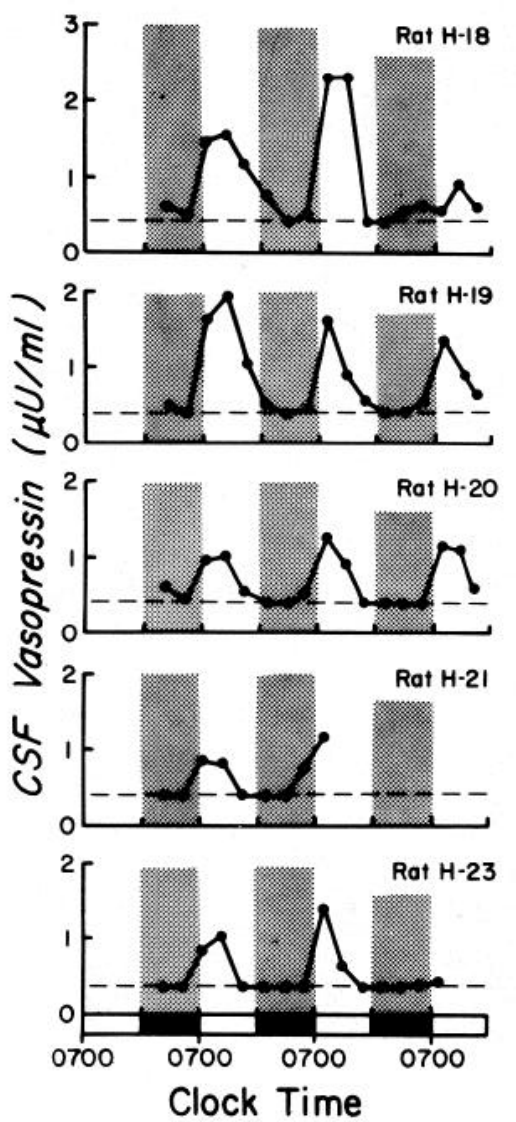

HYPOPHYSECTOMY

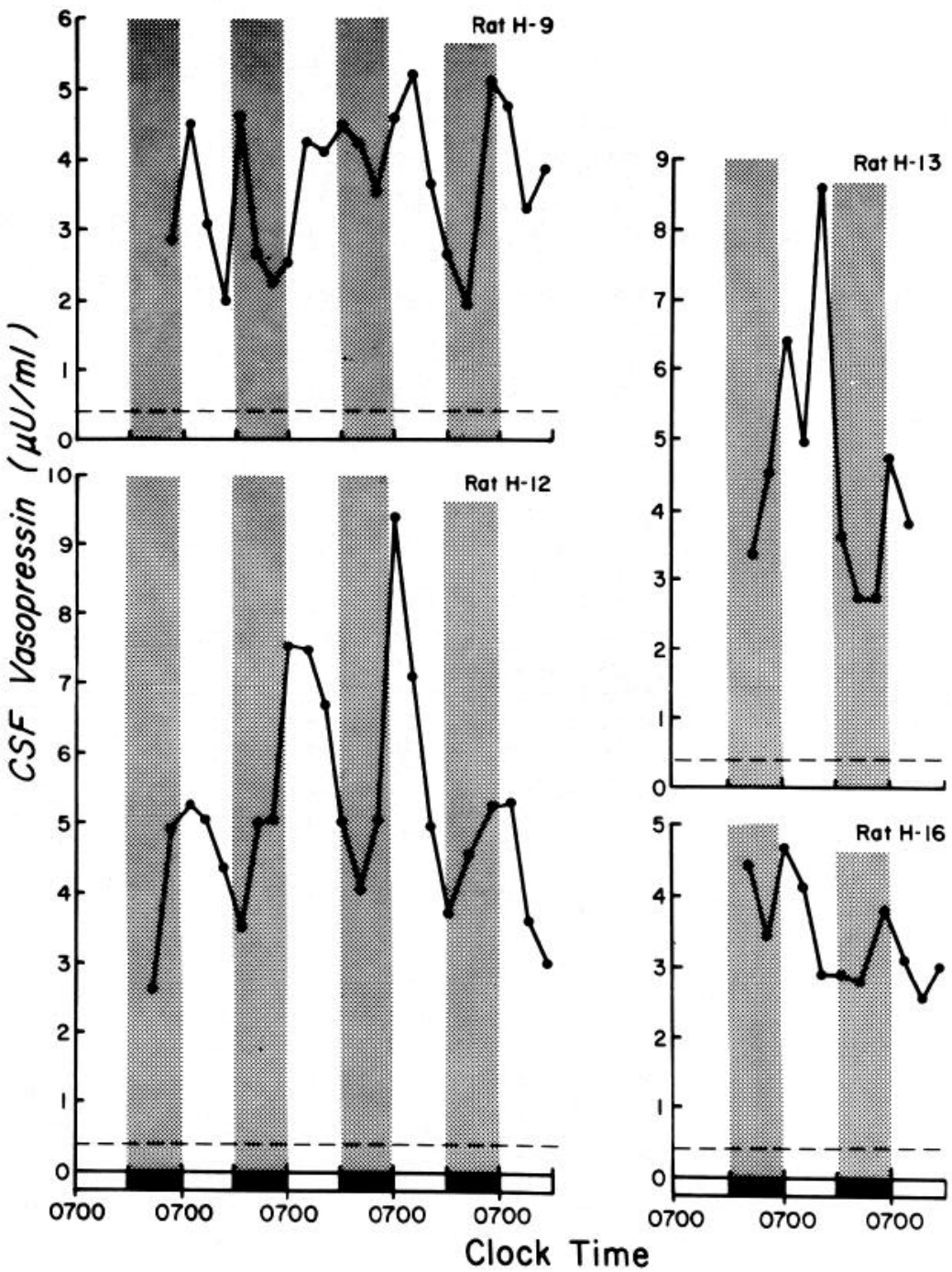

Figure 1. Patterns of CSF vasopressin for individual rats after hypophysectomy or sham procedure. Animals were studied in diurnal lighting (lights on from 7:00 A.M. to 7:00 P.M. hr). CSF was collected at the times indicated. The dashed lines indicate the lower limit of assay sensitivity.

some SCN perikarya (Buijs, 1983; Kozlowski et al., 1983; Sofroniew, 1983), the nuclei could generate the peptide rhythm either by periodically releasing the hormone or by regulating the timing of its release from another vasopressin-containing source.

Lesions of the paraventricular nuclei (PVN). We wished to examine the effects of PVN lesions on the CSF vasopressin rhythm because these nuclei contain substantial amounts of vasopressin, appear to receive SCN innervation (Berk and Finkelstein, 1981; Stephan et al., 1981; Card et ál., 1981), and may function as a relay for SCN control of at least one circadian rhythm, that of melatonin production by the pineal gland (Klein et al., 1983; Lehman et al., 1984).

Complete PVN lesions destroyed the magnocellular and parvocellular divisions of the nuclei and the immediately surrounding hypothalamic neuropil (Fig. 3B). The anterior commissural nucleus (Peterson, 1966) containing oxytocin (Rhodes et al., 1981; Sofroniew, 1983) was usually spared; SCN and supraoptic nuclei were undamaged in all cases. We confirmed recent reports that these lesions prevent the normal nocturnal elevation of pineal melatonin concentrations (Klein et al., 1983; Lehman et al., 1984) while leaving unaltered the rhythmicity of drinking activity (Pickard and Turek,
1983). High night-time melatonin levels after sham lesions $(2165 \pm$ $311 \mathrm{pg} / \mathrm{gland}$, SEM) were significantly blocked after either partial (163 $\pm 60 \mathrm{pg} / \mathrm{gland})$ or complete $(76 \pm 16 \mathrm{pg} / \mathrm{gland})$ lesions of the PVN $(p<0.05$, Kruskal-Wallis nonparametric one-way analysis of variance and multiple comparisons test) (Siegel, 1956).

The CSF vasopressin rhythm was present in all of these rats (Fig. 6), although amplitude was diminished in some of the lesioned animals. No relationship was found between rhythm amplitude and nocturnal melatonin concentrations.

Partial isolations of the SCN. Since additional vasopressin-containing perikarya are located outside the confines of the PVN, we performed knife cuts to interrupt neural efferents from the SCN and examined the effects on the CSF vasopressin rhythm.

All cuts at least partially isolated the SCN from the rest of the hypothalamus. Anteriorly and posteriorly, the knife reached the base of the brain. Islands extended caudally from the lamina terminalis to the anterior border of the medial basal hypothalamus. The lateral extent of the cuts was more difficult to discern, and in some cases the extreme inferolateral borders of the SCN were left intact (Fig. $3 C)$. In all animals with partial isolation of the SCN, nocturnal pineal 


\section{PINEALECTOMY}
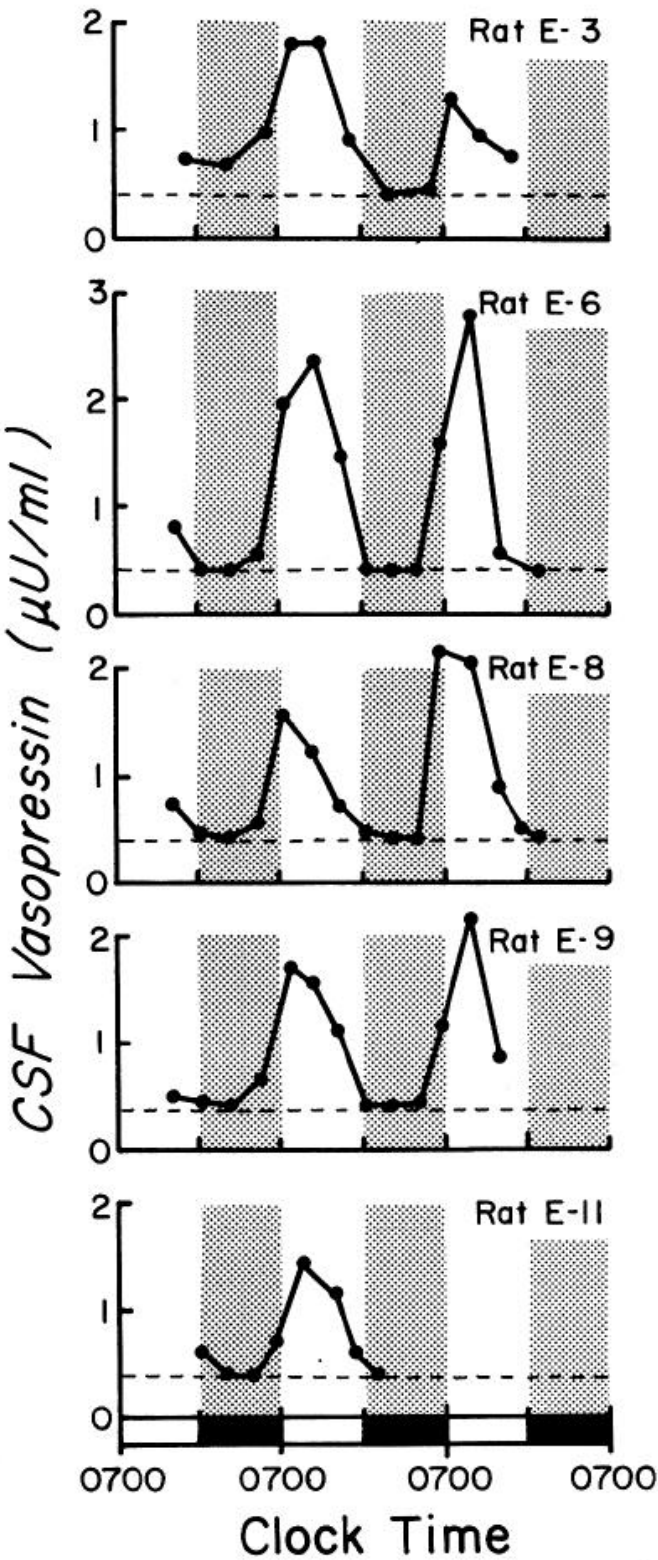

Figure 2. Patterns of CSF vasopressin for individual rats after pinealec tomy.

melatonin concentrations were depressed (301 \pm 106 pg/gland, SEM), and drinking activity showed no circadian periodicity by visual inspection and statistical analysis.

The vasopressin rhythm was present but clearly diminished $(<1$ micro-unit/ml of CSF) after partial isolations of the SCN (Fig. 7). In the two rats with unmeasurable peptide levels (Fig. 7, rats $1-31$ and I-36), the SCN were destroyed by the surgical procedure.

\section{Discussion}

Our data suggest that the circadian CSF vasopressin rhythm is produced by a neural system topographically separate from the classical magnocellular hypothalamo-neurohypophyseal system for the secretion of peptide into blood.

Neither the neurohypophysis nor the PVN are essential to the continued presence of vasopressin in CSF. Any contribution by
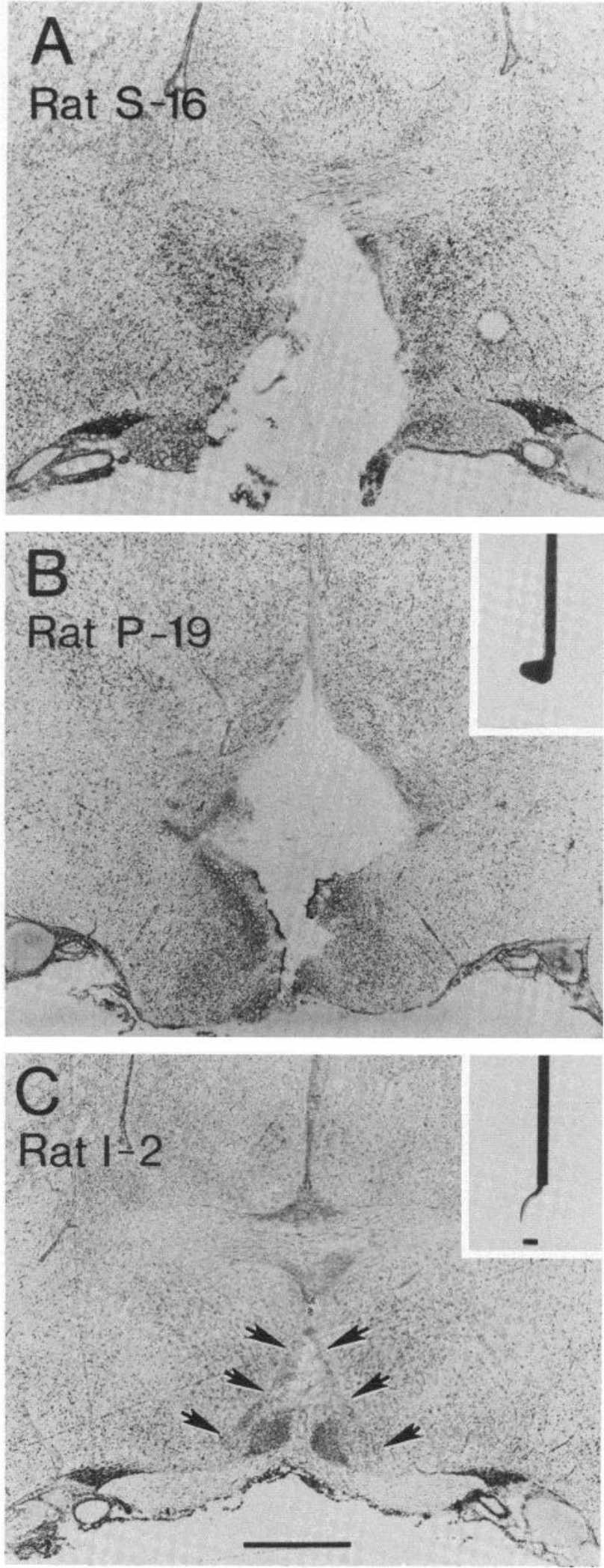

Figure 3. A, Coronal brain section from a rat with complete electrolytic lesion of the SCN. B, Coronal brain section from a rat with complete lesion of the PVN made by rotating a triangular microknife (inset). $C$, Coronal brain section from a rat with partial isolation (arrows) of the SCN made by rotating a wire microknife (inset). Cresylecht violet. Scale bars represent $1 \mathrm{~mm}$. 


\section{COMPLETE SCN LESION}
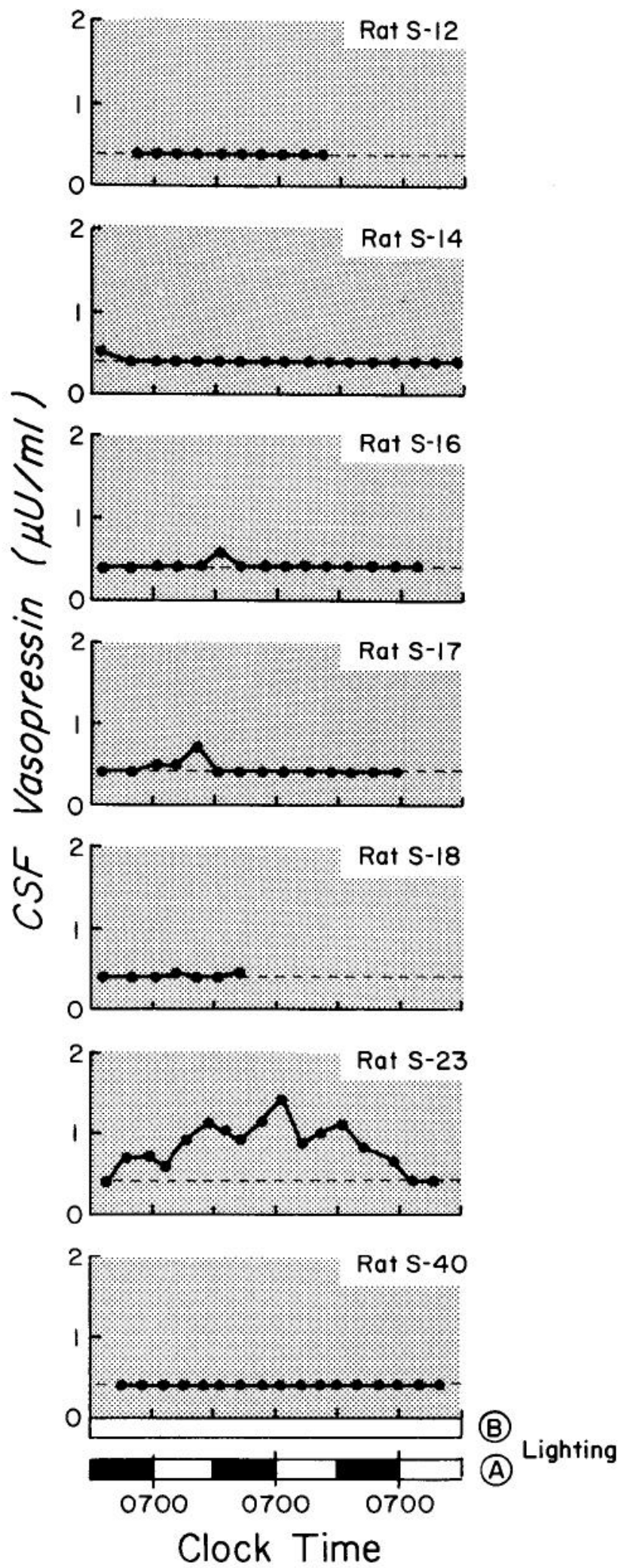

Figure 4. Patterns of CSF vasopressin for individual rats after complete SCN lesion. Animals were housed in diurnal lighting (regimen $A$ ) before they were blinded by bilateral orbital enucleation; lights were left on continuously after enucleation (regimen $B$ ). neurons in the supraoptic nuclei would also seem unlikely since they all appear to project to the neurohypophysis (Buijs, 1983; Kozlowski et al., 1983; Sofroniew, 1983; Swanson and Sawchenko, 1983). ${ }^{4}$ Our results also rule out the possibility that CSF vasopressin levels are due to high concentrations of peptide in hypophyseal portal plasma, whether by secretion from PVN terminals in the median eminence (Recht et al., 1981) or by retrograde transport from the neurohypophysis (Oliver et al., 1977). Elevated CSF vasopressin concentrations after hypophysectomy have been noted previously (Dogterom et al., 1977) and may be secondary to a massive penetration of new neurosecretory fibers into the third ventricle (Polenov et al., 1981).

Conversely, the SCN are an essential component of this CSF system. Lesions of the nuclei abolish both the rhythm and in most cases the measurable level of peptide in CSF. Since some of the cell bodies in the SCN contain vasopressin, the peptide in CSF may actually originate from these neurons. Another possibility is that the circadian oscillator located in the SCN may trigger vasopressin release from some other neural sites. For example, vasopressin cell bodies have now been identified in the bed nucleus of the stria terminalis, dorsomedial hypothalamus, medial amygdaloid nuclei, and locus ceruleus (Caffe and van Leeuwen, 1983; van Leeuwen and Caffe, 1983).

In order to address this issue, we performed knife cuts to interrupt neural efferents from the SCN. Although our isolations left the extreme inferolateral borders of the SCN intact in some cases, the cuts should have severed most SCN efferents because they course dorsally and caudally close to the midline (Berk and Finkelstein, 1981; Stephan et al., 1981; Watts and Swanson, 1984). In addition, we observed arrhythmicity of drinking activity after our partial isolations; simultaneous interruption of lateral, dorsal, and caudal fibers is required for this result (Nunez and Stephan, 1977).

Although rhythm periodicity survived our knife cuts, rhythm amplitude was clearly diminished. Our data do not yet allow an unequivocal interpretation for this result. Perhaps there exists a system of periventricular vasopressin-containing perikarya responsible for the rhythmic release of peptide into CSF; only some of these neurons would be located within the anatomical boundaries of the SCN. Our surgical procedure would have uncoupled a fraction of these neurons from the SCN oscillator that provides the daily signal for vasopressin release. However, an equally plausible scheme is that only vasopressin-containing cell bodies located in the SCN rhythmically release peptide into CSF. If this were the case, our knife cuts may have interrupted the axons of a subpopulation of these neurons that release peptide outside the anatomical boundaries of the nuclei (Hoorneman and Buijs, 1982). A third possibility is that rhythm amplitude is modulated by SCN afferents which were disconnected by the knife cuts.

The neuroanatomical system responsible for the circadian CSF vasopressin rhythm, along with the rhythm's phase conservation across species (Reppert et al., 1983) and effective insulation from osmotic regulation of blood vasopressin (Coleman and Reppert, 1985), suggests that the peptide has an important role in the mammalian circadian timekeeping system. Thus far, this notion has been pursued only in the homozygous Brattleboro rat (Wiley et al., 1974; Peterson et al., 1980; Groblewski et al., 1981; Brown and Nunez, 1984). A role for the peptide in normal individuals who do synthesize the hormone has not yet been investigated.

On the basis of the results presented here, we would anticipate

\footnotetext{
${ }^{4}$ We did attempt to make bilateral electrolytic lesions of the supraoptic nuclei, but mortality was high (>80\%) and lesions were not complete. In one surviving rat, with approximately $30 \%$ of each of the two nuclei intact posteriorly, a normal CSF vasopressin rhythm was found; in one other rat, with approximately $40 \%$ of one of the two nuclei undamaged, a peptide rhythm similar to that observed after hypophysectomy was found.
} 
Figure 5. Patterns of CSF vasopressin for individual rats after partial SCN lesion or sham procedure.
SHAM SCN LESION

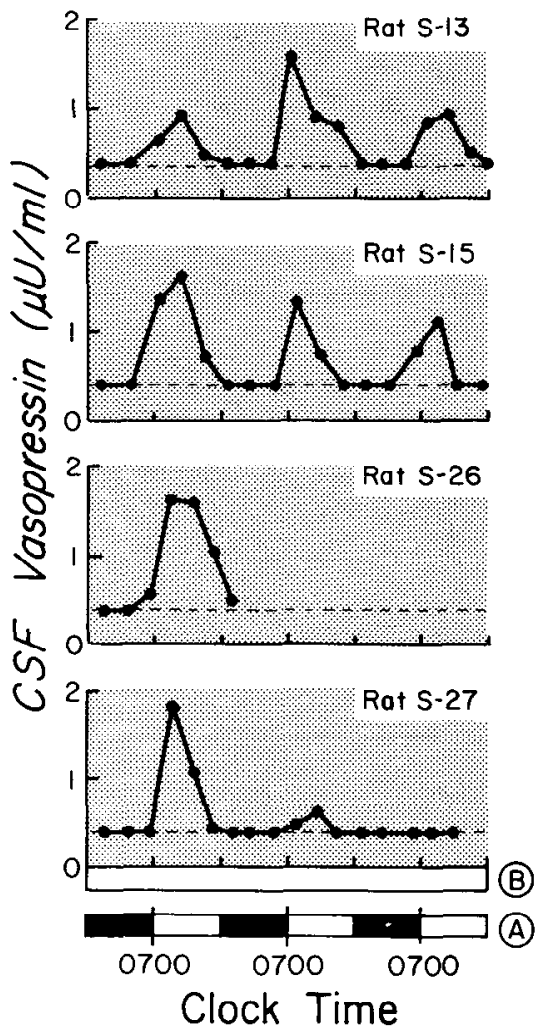

(A) Lighting
PARTIAL SCN LESION

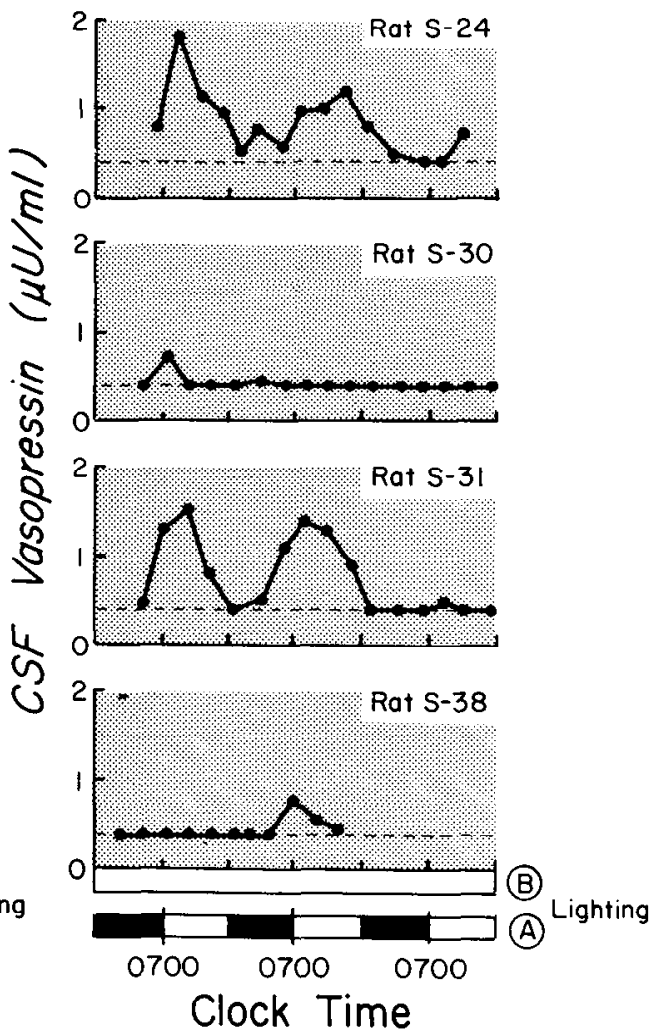

SHAM PVN LESION

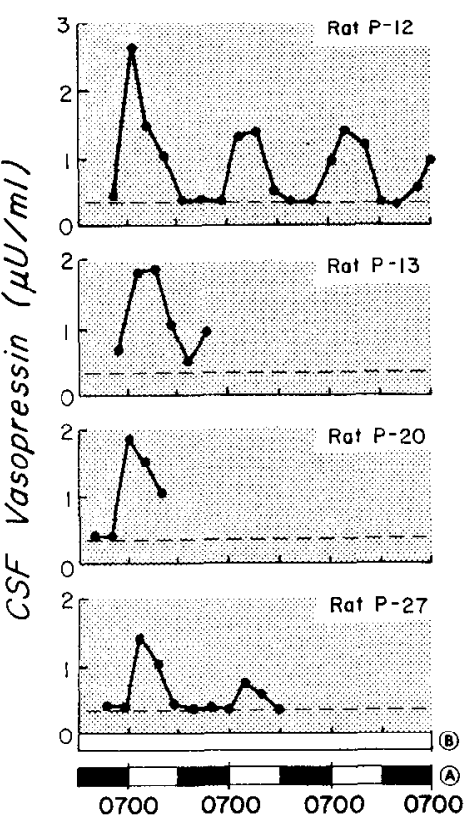

PARTIAL PVN LESION

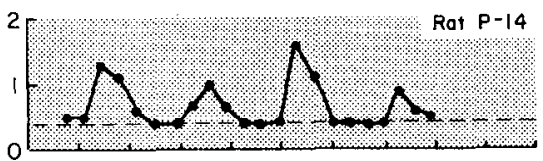

Rat P-15

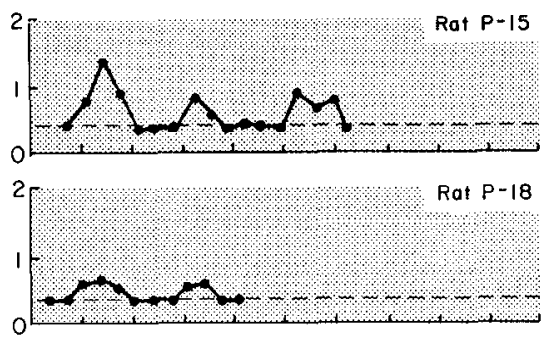

Rat $P-22$

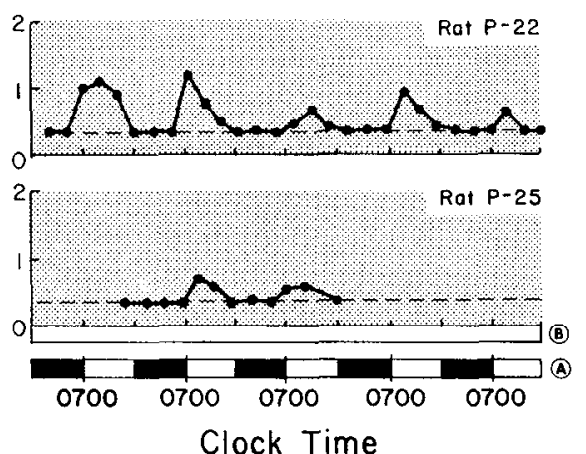

COMPLETE PVN LESION
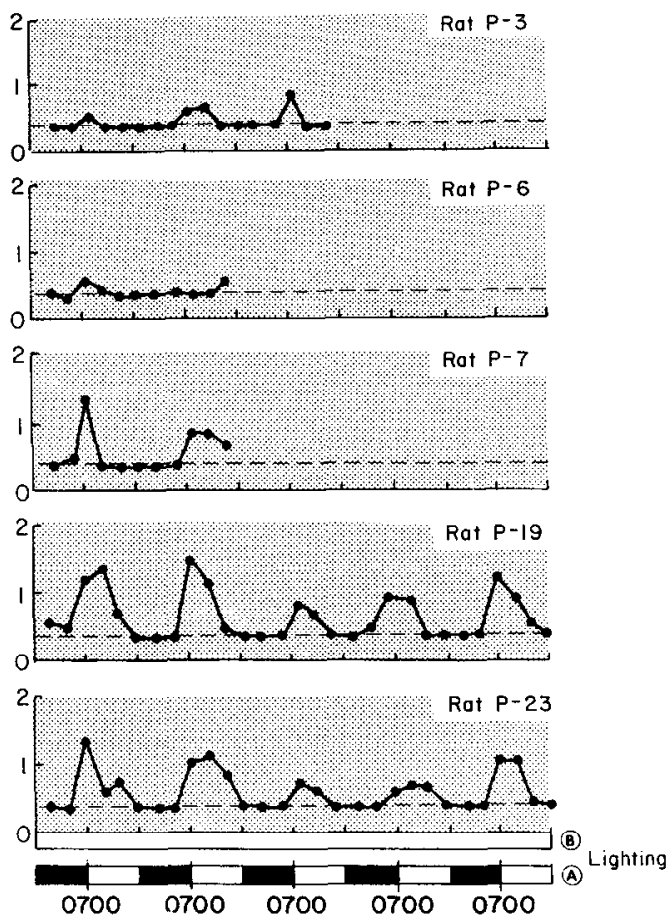

Figure 6. Patterns of CSF vasopressin for individual rats atter complete or partial PVN lesion or sham procedure. 


\section{HYPOTHALAMIC KNIFE CUTS}

\section{Partial SCN Isolation}
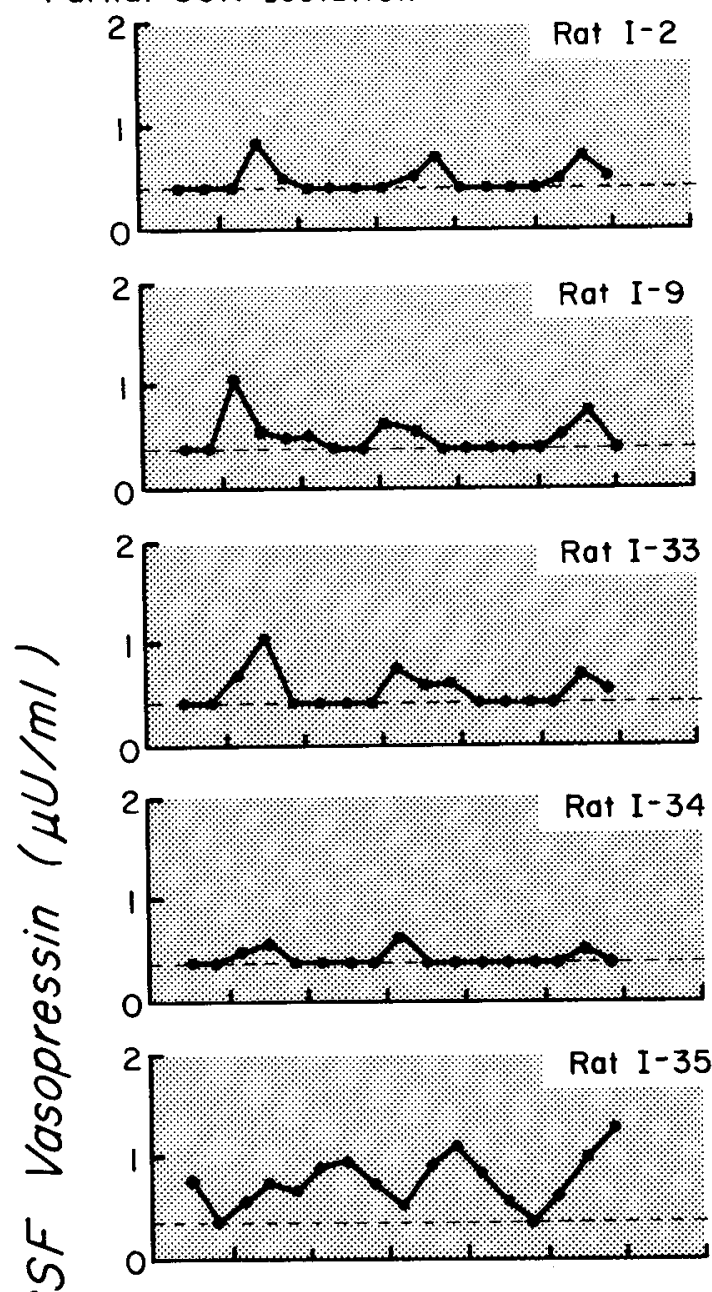

Complete SCN Destruction
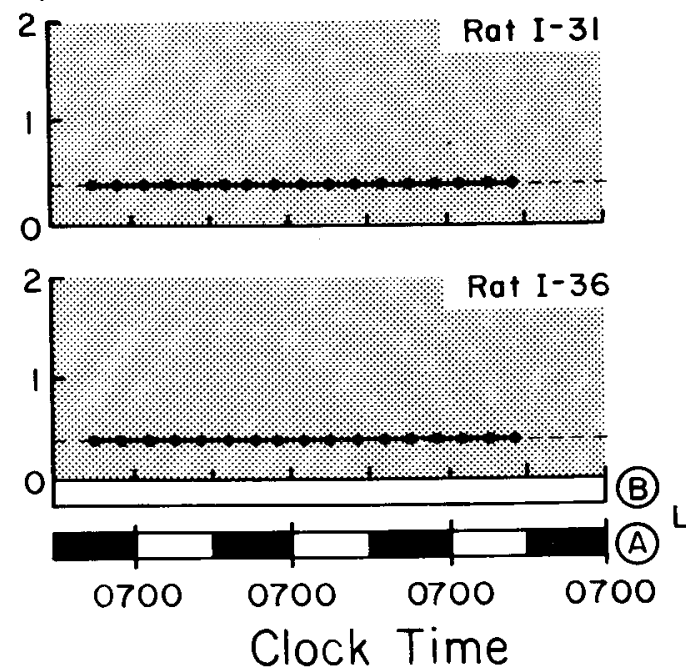

Figure 7. Patterns of CSF vasopressin for individual rats after hypothalamic knife cuts. that a tissue explant containing the SCN should be capable of periodic vasopressin release in vitro. In fact, preliminary work now substantiates this prediction (Earnest and Sladek, 1984). Although further study will be required, the rhythm of vasopressin release from the SCN may prove to be an important functional marker for the activity of the mammalian circadian clock located in the nuclei.

\section{References}

Ang, V. T. Y., and J. S. Jenkins (1982) Blood-cerebrospinal fluid barrier to arginine-vasopressin, desmopressin and desglycinamide arginine-vasopressin in the dog. J. Endocrinol. 93: 319-325.

Berk, M. L., and J. A. Finkelstein (1981) An autoradiographic determination of the efferent projections of the suprachiasmatic nucleus of the hypothalamus. Brain Res. 226: 1-13.

Brown, M. H., and A. A. Nunez (1984) Circadian sleep rhythms in vasopressin deficient Brattleboro rats. Soc. Neurosci. Abstr. 10: 501.

Buijs, R. M. (1983) Vasopressin and oxytocin-their role in neurotransmission. Pharmacol. Ther. 22: 127-141.

Buijs, R. M., and P. Pevet (1980) Vasopressin and oxytocin-containing fibers in the pineal gland and subcommissural organ of the rat. Cell Tissue Res. 205: 11-17.

Caffe, A. R., and F. W. van Leeuwen (1983) Vasopressin-immunoreactive cells in the dorsomedial hypothalamic region, medial amygdaloid nucleus and locus coeruleus of the rat. Cell Tissue Res. 233: 23-33.

Card, J. P., N. Brecha, H. J. Karten, and R. Y. Moore (1981) Immunocytochemical localization of vasoactive intestinal polypeptide-containing cells and processes in the suprachiasmatic nucleus of the rat: Light and electron microscopic analysis. J. Neurosci. 1: 1289-1303.

Coleman, R. J., and S. M. Reppert (1985) The cerebrospinal fluid vasopressin rhythm is effectively insulated from osmotic regulation of plasma vasopressin. Am. J. Physiol. 248: E346-E352.

Dogterom, J., T. B. van Wimersma Greidanus, and D. F. Swaab (1977) Evidence for the release of vasopressin and oxytocin into cerebrospinal fluid: Measurements in plasma and CSF of intact and hypophysectomized rats. Neuroendocrinology 24: 108-118.

Doris, P. A., and F. R. Bell (1984) Vasopressin in plasma and cerebrospinal fluid of hydrated and dehydrated steers. Neuroendocrinology 38: 290296.

Earnest, D. J., and C. D. Sladek (1984) Circadian rhythm in vasopressin release from rat suprachiasmatic explants in vitro. Soc. Neurosci. Abstr. 10: 500 .

Fisher, L. A., and J. D. Fernstrom (1981) Measurement of nonapeptides in pineal and pituitary using reversed-phase, ion-pair liquid chromatography with post-column detection by radioimmunoassay. Life Sci. 28: 14711481.

Groblewski, T. A., A. A. Nunez, and R. M. Gold (1981) Circadian rhythms in vasopressin deficient rats. Brain Res. Bull. 6: 125-130.

Gunther, O., R. Landgraf, J. Schuart, and H. Unger (1984) Vasopressin in cerebrospinal fluid and plasma of conscious rabbits-circadian variations. Exp. Clin. Endocrinol. 83: 367-369.

Hoorneman, E. M. D., and R. M. Buijs (1982) Vasopressin fiber pathways in the rat brain following suprachiasmatic nucleus lesioning. Brain Res. 243. 235-241.

Klein, D. C., R. Smoot, J. L. Weller, S. Higa, S. P. Markey, G. J. Creed, and D. M. Jacobowitz (1983) Lesions of the paraventricular nucleus area of the hypothalamus disrupt the suprachiasmatic-spinal cord circuit in the melatonin rhythm generating system. Brain Res. Bull 10: 647-652.

Kozlowski, G. P., G. Nilaver, and E. A. Zimmerman (1983) Distribution of neurohypophyseal hormones in the brain. Pharmacol. Ther. 21: 325-349.

Lehman, M. N., E. L. Bittman, and S. W. Newman (1984) Role of the hypothalamic paraventricular nucleus in neuroendocrine responses to daylength in the golden hamster. Brain Res. 308: 25-32.

Luerssen, T. G., and G. L. Robertson (1980) Cerebrospinal fluid vasopressin and vasotocin in health and disease. In Neurobiology of the Cerebrospinal Fluid, J. H. Wood, ed., Vol. 1, pp. 613-621, Plenum Press, New York.

Lighting Mens, W. B. J., H. J. Bouman, E. A. Bakker, and T. B. van Wimersma Greidanus (1980) Differential effects of various stimuli on AVP levels in blood and cerebrospinal fluid. Eur. J. Pharmacol. 68: 89-92.

Mens, W. B. J., E. A. D. Andringa-Bakker, and T. B. van Wimersma Greidanus (1982) Changes in cerebrospinal fluid levels of vasopressin and oxytocin of the rat during various light-dark regimes. Neurosci. Lett. 34: 51-56.

Moore, R. Y. (1983) Organization and function of a central nervous system oscillator: The suprachiasmatic hypothalamic nucleus. Fed. Proc. 42. 2783-2789. 
Morris, M., R. R. Barnard, Jr., and L. E. Sain (1984) Osmotic mechanisms regulating cerebrospinal fluid vasopressin and oxytocin in the conscious rat. Neuroendocrinology 39: 377-383.

Nelson, R. J., and I. Zucker (1981) Absence of extraocular photoreception in diurnal and nocturnal rodents exposed to direct sunlight. Comp. Biochem. Physiol. 69A: 145-148.

Nunez, A. A. and F. K. Stephan (1977) The effects of hypothalamic knife cuts on drinking rhythms and the estrus cycle of the rat. Behav. Biol. 20 . 224-234.

Oliver, C., R. S. Mical, and J. C. Porter (1977) Hypothalamic-pituitary vasculature: Evidence for retrograde blood flow in pituitary stalk. Endocrinology 101: 598-604

Perlow, M. J., S. M. Reppert, H. A. Artman, D. A. Fisher, S. M. Seif, and A. G. Robinson (1982) Oxytocin, vasopressin, and estrogen-stimulated neurophysin: Daily patterns of concentration in cerebrospinal fluid. Science 216: $1416-1418$.

Peterson, G. M., W. B. Watkins, and R. Y. Moore (1980) The suprachiasmatic nuclei of the rat. VI. Vasopressin neurons and circadian rhythmicity. Behav. Neural Biol. 29: 236-245

Peterson, R. P. (1966) Magnocellular neurosecretory centers in the rat hypothalamus. J. Comp. Neurol. 128: 181-190.

Pickard, G. E., and F. W. Turek (1983) The hypothalamic paraventricular nucleus mediates the photoperiodic control of reproduction but not the effects of light on the circadian rhythm of activity. Neurosci. Lett. 43: 6772.

Polenov, A. L., M. A. Belenky, and N. Bogdanovic-Stosic (1981) The hypothalamo-hypophyseal system of hypophysectomized rats. II. Structure and ultrastructure of the median eminence. Cell Tissue Res. 218: 607-622.

Recht, L.D., D. L. Hoffman, J. Haldar, A. J. Silverman, and E. A. Zimmerman (1981) Vasopressin concentrations in hypophyseal portal plasma: Insignificant reductions following removal of the posterior pituitary gland. Neuroendocrinology 33: 88-90.

Reppert, S. M., H. G. Artman, S. Swaminathan, and D. A. Fisher (1981) Vasopressin exhibits a rhythmic daily pattern in cerebrospinal fluid but not in blood. Science 213: 1256-1257.

Reppert, S. M., R. J. Coleman, H. W. Heath, and H. T. Keutman (1982) Circadian properties of vasopressin and melatonin rhythms in rat cerebrospinal fluid. Am. J. Physiol. 243: E489-E498.

Reppert, S. M., W. J. Schwartz, H. G. Artman, and D. A. Fisher (1983) Comparison of the temporal profiles of vasopressin and oxytocin in the cerebrospinal fluid of the cat, monkey and rat. Brain Res. 261: 341-345.

Rhodes, C. H., J. I. Morrell, and D. W. Pfaff (1981) Immunohistochemical analysis of magnocellular elements in rat hypothalamus: Distribution and numbers of cells containing neurophysin, oxytocin and vasopressin. $\mathrm{J}$. Comp. Neurol. 198: 45-64.

Rubirisun, I. C. A. F. (1983) Neurohypophyseal peptides in cerebrospinal fluid. Prog. Brain Res. 60: 129-145.

Robinson, I. C. A. F., and P. M. Jones (1982) Neurohypophyseal peptides in cerebrospinal fluid: Recent studies. In Vasopressin, Corticoliberin and Opiomelanocortins, A. J. Baertschi and J. J. Dreifuss, eds., pp. 21-32, Academic Press, London.
Rodbard, D. (1974) Statistical quality control and routine data processing for radioimmunoassays and immunoradiometric assays. Clin. Chem. 20 : $1255-1270$.

Rollag, M. D., and G. D. Niswender (1976) Radioimmunoassay of serum concentrations of melatonin in sheep exposed to different lighting regimens. Endocrinology 98: 482-488.

Rummel, J., J. K. Lee, and F. Halberg (1974) Combined linear-nonlinear chronobiologic windows by least squares resolve neighboring components in a physiologic rhythm spectrum. In Riorhythms and Hormone Reproduction, M. Ferin, F. Haiberg, R. M. Richart, and R. L. Vande Wiele, eds., pp. 53-82, John Wiley \& Sons, Inc., New York.

Schwartz, W. J., R. J. Coleman, and S. M. Reppert (1983) A daily vasopressin rhythm in rat cerebrospinal fluid. Brain Res. 263: 105-112.

Siegel, S. (1956) Nonparametric Statistics for the Behavioral Sciences, pp. 312, McGraw-Hill Book Co., New York.

Skowsky, W. R., A. A. Rosenbloom, and D. A. Fisher (1974) Radioimmunoassay measurement of arginine vasopressin in serum: Development and applicatıon. J. Clin. Endocrinol. Metab. 38: 278-287.

Sofroniew, M. V. (1983) Morphology of vasopressin and oxytocin neurons and their central and vascular projections. Prog. Brain Res. 60: 101-114.

Stark, R. I., S. S. Daniel, M. K. Husain, A. B. Zubrow, and L. S. James (1984) Effects of hypoxia on vasopressin concentrations in cerebrospinal fluid and plasma of sheep. Neuroendocrinology 38: 453-460.

Stephan, F. K., K. J. Berkley, and R. L. Ross (1981) Efferent connections of the rat suprachiasmatic nucleus. Neuroscience 6: 2525-2641.

Swanson, L.W., and P. E. Sawchenko (1983) Hypothalamic integration: Organization of the paraventricular and supraoptic nuclei. Annu. Rev. Neurosci. 6: 269-324.

Szczepanska-Sadowska, E., C. Simon-Oppermann, D. A. Gray, and E. Simon (1984) Plasma and cerebrospinal fluid vasopressin and osmolality in relation to thirst. Pflugers Arch. 400: 294-299.

Tamarkin, L., S. M. Reppert, and D. C. Klein (1979) Regulation of pineal melatonin in the Syrian hamster. Endocrinology 104: 385-389.

Underwood, H., and G. Groos (1982) Vertebrate circadian rhythms: Retinal and extraretinal photoreception. Experientia 38: 1013-1021.

van Leeuwen, F., and R. Caffe (1983) Vasopressin-immunoreactive cell bodies in the bed nucleus of the stria terminalis of the rat. Cell Tissue Res. 228: 525-534.

Wang, B. C., L. Share, J. T. Crofton, and T. Kimura (1981) Changes in vasopressin concentrations in plasma and cerebrospinal fluid in response to hemorrhage in anesthetized dogs. Neuroendocrinology 33: 61-66.

Wang, B. C., L. Share, J. T. Crofton, and T. Kimura (1982) Effect of intravenous and intracerebroventricular infusion of hypertonic solutions on plasma and cerebrospinal fluid vasopressin concentrations. Neuroendocrinology 34: 215-221.

Watts, A. G., and L. W. Swanson (1984) Evidence for a massive projection from the suprachiasmatic nucleus to a subparaventricular zone in the rat. Soc. Neurosci. Abstr. 10: 611 .

Wiley, M. K., A. F. Pearlmutter, and R. E. Miller (1974) Decreased adrenal sensitivity to ACTH in the vasopressin-deficient (Brattleboro) rat. Neuroendocrinology 14: 257-270. 